\title{
PROFILAXIA ANTIMICROBIANA PERIOPERATÓRIA: aplicação na rotina da clínica cirúrgica veterinária
}

\author{
Perioperative antimicrobial prophylaxis: application in \\ veterinary surgery routine
}

Mareliza Possa de Menezes ${ }^{1 \star}$ (D) Mayara Adrielli Ruaro²; Paola Castro Moraes ${ }^{3}$.

*Autor Correspondente: Mareliza Possa de Menezes. Via de Acesso Prof. Paulo Donato Castellane, s/n, Jaboticabal, São Paulo, SP, Brasil. CEP: 14884-900. E-mail: marelizamenezes@yahoo.com.br

\begin{abstract}
T Como citar: MENEZES, M. P. de; RUARO, M. A. ; MORAES, P. C. Profilaxia antimicrobiana perioperatória: aplicação na rotina da clínica cirúrgica veterinária. Revista de Educação Continuada em Medicina Veterinária e Zootecnia do CRMV-SP, São Paulo, v. 19, n. 1, 2021, e38111. DOI: https://doi.org/10.36440/recmvz. v19i1.38111.

Cite as: MENEZES, M. P. de; RUARO, M. A. ; MORAES, P. C. Perioperative antimicrobial prophylaxis: application in veterinary surgery routine. Journal of Continuing Education in Veterinary Medicine and Animal Science of CRMV-SP, São Paulo, v. 19, n. 1, 2021, e38111. DOl: https://doi.org/10.36440/recmvz.v19i1.38111.
\end{abstract}

\section{Resumo}

O uso de antimicrobianos para profilaxia antimicrobiana ocorre rotineiramente na clínica cirúrgica veterinária. Entretanto, há condições específicas para a sua indicação tanto para prevenir a ocorrência de infecção do sítio cirúrgico quanto para impedir a seleção de bactérias multirresistentes. 0 presente trabalho foi delineado para auxiliar médicos-veterinários na tomada de decisão em relação ao protocolo antimicrobiano aplicado em pacientes cirúrgicos, visando tanto o sucesso dos tratamentos quanto a redução na seleção e disseminação de bactérias multirresistentes no contexto de Saúde Única.

Palavras-chave: Antibiótico. Infecção do Sítio Cirúrgico. Falha Terapêutica. Resistência Antimicrobiana. Saúde Única.

\section{Abstract}

Antimicrobial prophylaxis is routinely applied in veterinary surgery. However, there are specific conditions for its use in order to prevent the occurrence of surgical site infection and the selection of multidrug-resistant bacteria. This review aimed to help veterinarians' surgeons in rational decision-making to the antimicrobial protocol applied in surgical patients. Thus, it was analysed not only how to achieve the treatment success, but also how to reduce the selection and spread of multidrug-resistant bacteria in the context of One Health.

Keywords: Antibiotic. Surgical Site Infection. Therapeutic Failure. Antimicrobial Resistance. One Health.

1 Doutoranda do Programa de Ciências Veterinárias da Faculdade de Ciências Agrárias e Veterinárias, Universidade Paulista "Júlio de Mesquita Filho", Jaboticabal, SP, Brasil

2 Discente do curso de graduação em Medicina Veterinária da Faculdade de Ciências Agrárias e Veterinárias, Universidade Paulista "Júlio de Mesquita Filho", Jaboticabal, SP, Brasil

3 Docente do Departamento de Clínica e Cirurgia Veterinária, Faculdade de Ciências Agrárias e Veterinárias, Universidade Paulista "Júlio de Mesquita Filho", Jaboticabal, SP, Brasil 


\section{Introdução}

A profilaxia antimicrobiana cirúrgica consiste na administração de antimicrobianos em paciente que não possui foco de infecção no momento do procedimento cirúrgico. 0 seu objetivo é reduzir a carga microbiana no sítio cirúrgico no momento da abordagem de tal forma que as defesas normais do hospedeiro possam prevenir a infecção pós-operatória (BOOTHE; BOOTHE, 2015).

A falta de padronização e o uso indiscriminado de antimicrobianos em pacientes cirúrgicos veterinários são apontados como as principais causas de infecções do sítio cirúrgico e do aumento na frequência de resistência bacteriana (ROUSH, 1999; LEVY, 2002; NAPIER et al., 2013). As estirpes bacterianas multirresistentes apresentam potencial zoonótico e podem ser disseminadas aos seres humanos, principalmente tutores e profissionais veterinários (KASPAR et al., 2018; MCEWEN; COLLIGNON, 2018).

Considerando a importância da adoção de boas práticas cirúrgicas e do uso racional de antimicrobianos no setor de cirurgia veterinária, visando o sucesso dos tratamentos e a redução na seleção e disseminação de bactérias multirresistentes no contexto de Saúde Única, essa revisão aborda conceitos sobre profilaxia antimicrobiana aplicada na rotina cirúrgica veterinária.

\section{Infecção do sítio cirúrgico e fatores de risco}

A infecção do sítio cirúrgico (ISC) é definida como a que ocorre em até 30 dias após o procedimento ou em até um ano quando são empregados implantes internos (HORAN, 1992; ECDC, 2013; BURGESS, 2019). Apesar de ainda incerto na Medicina Veterinária, estima-se que a taxa de ISC entre os pacientes submetidos à cirurgia seja de até 5,9\% em procedimentos considerados limpos e limpos-contaminados, $5,8 \%$ em procedimentos contaminados e $18,1 \%$ em procedimentos infectados (WEESE; HALLING, 2006; WEESE, 2008; SINGH; WEESE, 2017; VERWILGHEN; SINGH, 2015).

O risco de infecção em pacientes cirúrgicos depende da susceptibilidade da ferida cirúrgica à contaminação microbiana, e os fatores de risco associados à sua ocorrência estão relacionados ao paciente, ao ambiente, ao tipo de procedimento e aos microrganismos presentes no sítio cirúrgico, descritos na Tabela 1 (VERWILGHEN; SINGH, 2015; ALLEGRANZI et al., 2016; BURGESS, 2019).

Tabela 1: Fatores de risco para o desenvolvimento da infecção do sítio cirúrgico.

\begin{tabular}{|c|c|c|}
\hline Paciente & Procedimento/Ambiente & Microrganismo \\
\hline Idade & Descontaminação das mãos do cirurgião & Colonização prévia* \\
\hline Obesidade ou desnutrição & Potencial de contaminação da ferida & Virulência \\
\hline Infecção à distância & Duração da anestesia/cirurgia & Aderência \\
\hline Neoplasia & Cirurgia de urgência & Inóculo \\
\hline $\begin{array}{l}\text { Controle glicêmico } \\
\text { inapropriado* }\end{array}$ & $\begin{array}{c}\text { Remoção dos pelos e preparo } \\
\text { inadequado da pele do paciente* }\end{array}$ & $\cdots$ \\
\hline Imunossupressão & Hipotermia* & $\ldots$ \\
\hline Classificação ASA & Profilaxia cirúrgica inadequada* & $\ldots$ \\
\hline Hipotensão & Contaminação intraoperatória* & $\ldots$ \\
\hline$\ldots$ & Falha nas técnicas de hemostasia & $\ldots$ \\
\hline
\end{tabular}




\begin{tabular}{|c|c|c|}
\hline$\ldots$ & Excesso de pessoas na sala operatória* & $\ldots$ \\
\hline$\ldots$ & $\begin{array}{c}\text { Ausência ou inadequação de protocolos } \\
\text { de curativos* }\end{array}$ & $\ldots$ \\
\hline$\ldots$ & Oxigenação* & $\ldots$ \\
\hline$\ldots$ & Falha na hemostasia & $\ldots$ \\
\hline$\ldots$ & Ventilação da sala operatória* & $\ldots$ \\
\hline
\end{tabular}

*Fatores de risco modificáveis

T Fonte: OMS, 2014; SINGH et al., 2013; WALTHER; TEDIN; LüBKE-BECKER, 2016; BURGESS, 2019.

\section{A profilaxia sempre diminui o risco de infecção?}

A profilaxia cirúrgica possui eficácia limitada e não diminui o risco de infecção em caso de quebra de técnica, dessa forma não deve substituir as boas práticas cirúrgicas e as medidas adequadas de assepsia (DUNNING, 2003; HOWE; BOOTHE, 2006; BOOTHE; BOOTHE, 2015). Dentre todos os fatores de risco expostos, alguns são passíveis de controle pela equipe cirúrgica e anestésica, portanto, para reduzir a incidência de infecção do sítio cirúrgico é necessária a abordagem sistemática desses pontos-chave, incluindo boa comunicação com a equipe, boa comunicação com o proprietário sobre os cuidados com a ferida no pós-operatório, diagnóstico precoce da infecção e identificação da profundidade e extensão da infecção (VERWILGHEN; SINGH, 2015; CHAUVEAUX, 2015).

É importante ressaltar que, apesar da profilaxia cirúrgica reduzir a prevalência da ISC, essas práticas não são suficientes para impedir a sua ocorrência, dessa forma o médico-veterinário deve comunicar ao proprietário as taxas de incidência de ISC (PLOWMAN, 2000; SINGH; WEESE, 2017). Para diminuir os riscos da infecção do sítio cirúrgico é proposta a realização de uma lista de checagem perioperatória, que garanta uma abordagem segura (Anexo 1).

\section{Quando e como realizar?}

A administração de antimicrobiano profilático deve ocorrer no pré-operatório dentro de 30 a 60 minutos (120 minutos para fluorquinolonas) antes da incisão cirúrgica em: a) cirurgias contaminadas e infectadas; b) cirurgias limpas-contaminadas com tempo cirúrgico maior que 90 minutos; c) cirurgias limpas-contaminadas com abordagem de órgãos ocos; e d) cirurgias com aplicação de implante interno (AIKEN et al., 2015; BOOTHE; BOOTHE, 2015). Nesses casos, a administração deve ser repetida a cada 90 minutos após a dose inicial, com exceção para as fluorquinolonas, em que não devem ser administradas doses adicionais (BOOTHE; BOOTHE, 2015; VERWILGHEN; SINGH, 2015).

A classificação da ferida cirúrgica ocorre de acordo com o nível de contaminação e do potencial para desenvolvimento da infecção (Anexo 2).

\section{Quais os fármacos e as doses recomendadas para profilaxia cirúrgica}

A seleção dos antimicrobianos para profilaxia e terapêutica deve ser baseada no conhecimento da microbiota esperada, capacidade do fármaco para atingir o tecido alvo em concentrações apropriadas, padrões de resistência bacteriana, farmacocinética e farmacodinâmica, além de testes de cultura e 
suscetibilidade (HOWE; BOOTHE, 2006). 0 fármaco utilizado na profilaxia precisa atingir níveis séricos bactericidas, ou seja, alcançar a concentração inibitória mínima nos tecidos alvos, anteriormente a realização da primeira incisão (BRAGAS et al., 2012; BOOTHE; BOOTHE, 2015).

A cefazolina $(25 \mathrm{mg} / \mathrm{kg}$, IV), cefalosporina de primeira geração, é um fármaco bactericida que apresenta concentrações apropriadas na maioria dos tecidos quando administrada pela via intravenosa, prevenindo o crescimento bacteriano na ferida cirúrgica. Nos casos de procedimentos nos segmentos de intestino grosso e trato biliar, ou outras áreas contendo enterobactérias e bactérias anaeróbicas, a profilaxia antimicrobiana deve considerar agentes com ampla cobertura para tais microrganismos, como a cefoxitina $(25 \mathrm{mg} / \mathrm{kg}, \mathrm{VV})$, cefalosporina de segunda geração. Já as cefalosporinas de terceira geração, como ceftriaxona, ceftiofur e cefovecina, não são indicadas na profilaxia antimicrobiana em cirurgias limpas e limpas-contaminadas e o seu uso deve ser restrito a pacientes críticos por se tratarem de antibióticos de amplo espectro de ação (HOWE; BOOTHE, 2006; BOOTHE; BOOTHE, 2015).

É importante ressaltar que agentes utilizados na profilaxia cirúrgica, como cefalosporinas, devem ser evitados no tratamento de infecções clínicas no ambiente hospitalar, reduzindo a emergência de estirpes de bactérias resistentes a esses fármacos no ambiente cirúrgico (HOWE; BOOTHE, 2006). A Tabela 2 apresenta os fármacos indicados para cada tipo de procedimento cirúrgico.

Tabela 2. Procedimento cirúrgico, patógenos prováveis e antimicrobiano recomendado na aplicação da profilaxia antimicrobiana cirúrgica.

\begin{tabular}{|c|c|c|}
\hline Procedimento & Patógenos prováveis & Antimicrobiano recomendado \\
\hline Pele & $\begin{array}{l}\text { Staphylococcus ssp., mais } \\
\text { comumente S. pseudointermedius }\end{array}$ & Cefazolina \\
\hline Cabeça e pescoço & $\begin{array}{c}\text { Staphylococcus spp., Streptococcus } \\
\text { spp., anaeróbias }\end{array}$ & Clindamicina ou cefazolina \\
\hline $\begin{array}{c}\text { Ortopedia (eletiva, } \\
\text { fratura fechada) e } \\
\text { neurocirurgia }\end{array}$ & Staphylococcus spp. & Cefazolina \\
\hline $\begin{array}{l}\text { Ortopedia (fraturas } \\
\text { abertas) }\end{array}$ & $\begin{array}{c}\text { Staphylococcus spp., Streptococcus } \\
\text { spp. Enterobactérias }\end{array}$ & Cefazolina \\
\hline $\begin{array}{l}\text { Cirurgias } \\
\text { cardiotorácicas }\end{array}$ & Staphylococcus spp. & Cefazolina \\
\hline Gastroduodenal & $\begin{array}{c}\text { Bacilos gram-negativos entéricos, } \\
\text { cocos gram-positivos }\end{array}$ & Cefazolina \\
\hline $\begin{array}{l}\text { Trato gastrointestinal } \\
\text { baixo }\end{array}$ & $\begin{array}{c}\text { Enterococcus spp., bacilos gram- } \\
\text { negativos e anaeróbicos }\end{array}$ & Cefoxitina \\
\hline Vesícula biliar e fígado & $\begin{array}{l}\text { Clostridium spp., bacilos gram- } \\
\text { negativos e anaeróbios }\end{array}$ & Cefoxitina \\
\hline Urogenital & $\begin{array}{l}\text { E. coli, Proteus spp., } \\
\text { Staphylococcus spp. }\end{array}$ & $\begin{array}{l}\text { Cefazolina (Staphylococcus spp.) ou } \\
\text { Enrofloxacina (enterobactérias) }\end{array}$ \\
\hline
\end{tabular}

TFonte: Adaptada de PAUL et al., 2012; VERWILGHEN; SINGH, 2015; HANGMAN, 2018. 


\section{Devo continuar a profilaxia no pós-operatório?}

Não, o risco de contaminação bacteriana ocorre até o desenvolvimento de selo de fibrina nas bordas da ferida, o que acontece entre 3-5h após o término do procedimento. Após esse período, a continuação da administração do antimicrobiano não apresenta eficácia e pode aumentar o risco de infecção por bactérias multirresistentes. Em casos de infecção diagnosticada, a terapia antimicrobiana deve ser iniciada no pós-operatório de acordo com os resultados dos testes de susceptibilidade (BOOTHE; BOOTHE, 2015; VERWILGHEN; SINGH, 2015). A extensão da profilaxia também não é recomendada quando são aplicadas sondas, cateteres ou drenos, pois, além de aumentar a seleção de bactérias multirresistentes, ela não é eficaz em tais situações (ALLEGRANZI et al., 2016).

\section{Quais os cuidados com a ferida cirúrgica no pós- operatório?}

Em feridas cirúrgicas limpas e limpas-contaminadas não é recomendada a aplicação de agentes antimicrobianos tópicos. É de extrema importância a realização dos curativos de forma asséptica, ter boa comunicação com o proprietário para identificação precoce e eficaz da ISC, e estar sempre atento aos sinais de inflamação e infecção (BOOTHE; BOOTHE, 2015).

\section{Diagnosticando a ISC}

O diagnóstico precoce e assertivo é indispensável para o sucesso do tratamento da ISC. Pacientes com infecção da ferida cirúrgica poderão apresentar no local da incisão: hiperemia, dor, edema, secreção, aumento de temperatura, deiscência de sutura, presença de abscesso e/ou fistulações. Também poderão apresentar sinais sistêmicos como febre, principalmente em relação à ISC profundo, podendo evoluir para sepse em casos graves (AIKEN et al., 2015, PRATESI et al., 2015).

Quando forem observados três ou mais dos sinais suprarreferidos ou quando houver a presença de secreção purulenta, considera-se que a ferida cirúrgica está infectada (PRATESI et al., 2015).

\section{Identifiquei ISC, como proceder?}

Primeiramente, deve-se identificar a profundidade e a extensão da infecção (Figura 1). Quando são identificados sinais de ISC incisional superficial, é indicada a retirada de pontos, drenos ou implantes presentes na ferida cirúrgica, quando possível, seguido da aplicação de biocidas ou antimicrobianos de uso tópico quando necessário (SINGH; WEESE, 2017). 
Figura 1. Classificação anatômica da infecção do sítio cirúrgico de acordo com o grau de invasividade da incisão

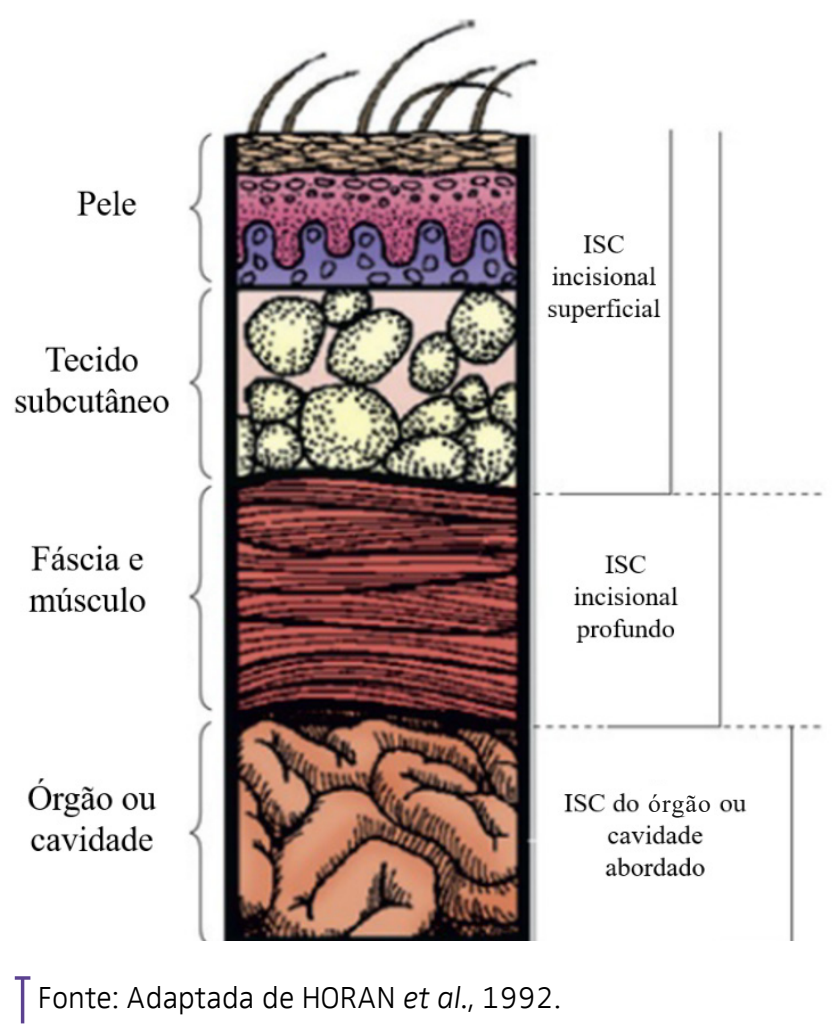

A terapia antimicrobiana sistêmica será instituída apenas em casos de ISC superficial que não apresente melhora após terapia tópica e ISC incisional profunda ou do órgão/cavidade abordado. As feridas infectadas devem ser tratadas no pós-operatório com fármacos antimicrobianos, baseado nos testes de cultivo e susceptibilidade, até dois ou três dias após a resolução dos sinais clínicos (HOWE; BOOTHE, 2006; SINGH; WEESE, 2017).

Espécies de Staphylococcus spp., enterobactérias (Escherichia coli, Proteus mirabilis e Klebsiella spp.) e Pseudomonas aeruginosa são os patógenos mais comuns em infecções hospitalares e na ISC, em humanos e animais (TURK; SINGH; WEESE, 2014; ANDRADE et al. 2016; WALTHER; TEDIN; LüBKEBECKER, 2016; CHAUDHARY et al. 2017; SHOEN et al. 2019). No Brasil, essas espécies também têm sido as mais frequentes no ambiente cirúrgico e hospitalar da medicina veterinária (GOBBO et al., 2017; FERNANDO et al., 2015; MURTA et al., 2015; MENEZES et al., 2020). A indicação de profilaxia antimicrobiana cirúrgica é descrita na Tabela 2.

\section{Conclusão}

A profilaxia antimicrobiana cirúrgica é indicada em condições específicas para minimizar a ocorrência de infecção do sítio cirúrgico, processo patológico que afeta a condição geral do paciente, aumenta gastos com sua recuperação e propicia a seleção de bactérias multirresistentes, acarretando graves impactos não apenas na saúde animal como na saúde humana. Os principais pontos a serem considerados são: controle dos fatores de risco, tipo de procedimento cirúrgico, patógenos prováveis, sítio da cirurgia e o grau de invasividade da incisão.\& 


\section{Referências}

AIKEN, M. J. et al. Prospective, randomized comparison of the effect of two antimicrobial regimes on surgical site infection rate in dogs undergoing orthopedic implant surgery. Veterinary Surgery, Philadelphia, v. 44, n. 5, p. 661-667, jul. 2015. DOI: https://doi.org/10.1111/vsu.12327.

ALLEGRANZI, B. et al. New WHO recommendations on intraoperative and postoperative measures for surgical site infection prevention: an evidence-based global perspective. The Lancet Infectious Diseases, New York, v. 16, n. 12, p. e288-e303, dec. 2016. Dol: https://doi.org/10.1016/S14733099(16)30402-9.

ANDRADE, N. et al. Survey of intraoperative bacterial contamination in dogs undergoing elective orthopedic surgery. Veterinary Surgery, Philadelphia, v. 45, n. 2, p. 214-222, feb. 2016. DOI: https:// doi.org/10.1111/vsu.12438.

BRAGA, D. P. et al. Antibioticoprofilaxia em cirurgias de cães e gatos: necessidade e realidade. Revista Ceres, Viçosa, v. 59, n. 6, p. 758-764, nov.-dez. 2012. Dol: https://doi.org/10.1590/S0034737X2012000600004.

BOOTHE, D. M.; BOOTHE H. W. Antimicrobial considerations in the perioperative patient. Veterinary Clinics of North America: Small Animal Practice, Philadelphia, v. 45, n. 3, p. 585-608, may 2015. DOI: https://doi.org/10.1016/j.cvsm.2015.01.006.

BURGESS, B. A. Prevention and surveillance of surgical infections: A review. Veterinary Surgery, Philadelphia, v. 48, n. 3, p. 284-290, apr. 2019. DOl: https://doi.org/10.1111/vsu.13176.

CHAUDHARY R. et al. Surgical Site Infections and Antimicrobial Resistance Pattern. Journal of Nepal Health Research Council, Kathmandu, v. 15, n. 2, p. 120-123, sep. 2017. D0I: https://doi. org/10.3126/jnhrc.v15i2.18185.

CHAUVEAUX D. Preventing surgical-site infections: Measures other than antibiotics. Orthopaedics \& Traumatology: Surgery \& Research, Issy les Moulineaus, v. 101, n. 1, Suplement, p. S77-S83, feb. 2015. DOl: https://doi.org/10.1016/j.otsr.2014.07.028.

DUNNING, D. Surgical wound infection and the use of antimicrobials. in: SLATTER D. (ed.). Textbook of small animal surgery (ed 3). Philadelphia: Saunders, 2003, p. 113-121.

EUROPEAN CENTRE FOR DISEASE CONTROL AND PREVENTION (ECDC). Point prevalence survey of healthcare associated infections and antimicrobial use in European acute care hospitals, 2013. Disponivel em: https://www.ecdc.europa.eu/sites/default/files/media/en/publications/Publications/ healthcare-associated-infections-antimicrobial-use-PPS.pdf. Acesso em: 19 maio 2021.

GOBBO, J. L. et al. Evaluation of operating room environment contamination and efficacy of $2 \%$ chlorhexidine for surgical hand scrubbing before and after gowning and gloving. Acta Scientiae Veterinariae, Porto Alegre, v. 45, n. 1484, p. 1-10, sep. 2017. Disponível em: https://seer.ufrgs.br/ ActaScientiaeVeterinariae/article/view/80500/47234. Acesso em: 19 de maio 2021.

HANGMAN, R. Pyometra in small animals. Veterinary Clinics of North America: Small Animal Practice, Philadelphia, v. 48, n. 4, p. 639-661, jul. 2018. DOl: https://doi.org/10.1016/S01966553(05)80201-9.

HORAN, T. C. et al. CDC Definitions of Nosocomial Surgical Site Infections, 1992: A modification of CDC definitions of surgical wound infections. American Journal of Infection Control, Thorofare, v. 13, n. 10, p. 606-608, oct. 1992. DOI: https://doi.org/10.1016/S0196-6553(05)80201-9. 
HOWE, L. M.; BOOTHE, H. W. Antimicrobial use in the surgical patient. Veterinary Clinics of North America: Small Animal Practice, Philadelphia, v. 36, n. 5, p. 1049-1060, sep. 2006. D0l: https://doi. org/10.1016/j.cvsm.2006.05.001.

KASPAR, U. Zoonotic multidrug-resistant microorganisms among small companion animals in Germany. PLoS One, San Francisco, v. 13, n. 12, p. 1-15, dec. 2018. Dol: https://doi.org/10.1371/ journal.pone.0208364.

LEVY, S. B. The 2000 Garrod lecture. Factors impacting on the problem of antibiotic resistance. Journal of Antimicrobial Chemotherapy, London, v. 49, n. 1, p. 25-30, jan. 2002. D0l: https://doi. org/10.1093/jac/49.1.25.

MCEWEN, S. A.; COLLIGNON, P. J. Antimicrobial resistance: a one health perspective. Microbiology Spectrum, Washington, v. 6, n. 2, p. 1-26, mar. 2018. DOl: https://doi.org/10.1128/microbiolspec. ARBA-0009-2017.

MENEZES, M. P. et al. Evaluation of the resistance profile of bacteria obtained from infected sites of dogs in a veterinary teaching hospital in Brazil: a retrospective study. Topics in Companion Animal Medicine, New York, v. 42 p. 2-6, marc. 2021. DOl: http://dx.doi.org/10.1016/j.tcam.2020.100489.

MURTA, A. R. et al. Perfil epidemiológico e análise microbiológica da infecção de sítio cirúrgico em pacientes humanos e animais de companhia. Pesquisa Veterinária Brasileira, v. 35, n. 7, p. 652-658, jul. 2015. DOl: http://dx.doi.org/10.1590/S0100-736X2015000700009.

NAPIER, B. A. et al. Clinical use of colistin induces cross-resistance to host antimicrobials in Acinetobacter baumannii. mBio, Washington, v. 4, n. 3, e00021-13, may. 2013. D0l: https://doi. org $/ 10.1128 / \mathrm{mBio} .00021-13$.

ORGANIZAÇÃO MUNDIAL DA SAÚDE. Segundo desafio global para a segurança do paciente: cirurgias seguras salvam vidas (orientações para cirurgia segura da OMS). Organização Mundial da Saúde, Rio de Janeiro: Organização Pan-Americana da Saúde; Ministério da Saúde; Agência Nacional de Vigilância Sanitária, 2009. Disponível em: http://bvsms.saude.gov.br/bvs/publicacoes/ seguranca paciente cirurgias seguras salvam vidas.pdf. Acesso em: 19 de maio. 2021.

PAUL, N. C. et al. Staphylococcus pseudintermedius colonization patterns and strain diversity in healthy dogs: A cross-sectional and longitudinal study. Veterinary Microbiology, Amsterdam, v. 160, n. 3-4, p. 420-427, dec. 2012. DOl: https://doi.org/10.1016/j.vetmic.2012.06.012.

PLOWMAN, R. The socioeconomic burden of hospital acquired infection. Euro Surveill, Saint-Maurice, v. 5, n. 4, p. 49-50, apr. 2000. DOl: https://doi.org/10.2807/esm.05.04.00004-en.

PRATESI, A. et al. Efficacy of postoperative antimicrobial use for clean orthopedic implant surgery in dogs: a prospective randomized study in 100 consecutive cases. Veterinary Surgery, Philadelphia, v. 44, n. 5, p. 653-660, jul. 2015. DOl: https://doi.org/10.1111/vsu.12326.

ROUSH, J. K. Controle de infecção. In: HARARI, J, (ed.). Cirurgias de pequenos animais. Porto Alegre: Artmed, 1999. 420p.

SINGH, A. et al. Characterization of the biofilm forming ability of Staphylococcus pseudintermedius from dogs. BMC Veterinary Research, London, v. 9, p. 93-98, may. 2013. DOI: https://doi. org/10.1186/1746-6148-9-93.

SINGH, A.; WEESE, J. S. Wound infections and antimicrobial use. In: JOHNSTON, S. A.; TOBIAS, K. M. (ed.). Veterinary Surgery: Small Animal. 2. ed. New York: Elsevier, 2017. v. 1, chap. 10, p. 530-548.

SHOEN, H. R. C. et al. Analysis of staphylococcus infections in a veterinary teaching hospital from 2012 to 2015. Comparative Immunology, Microbiology and Infectious Diseases, Oxford, v. 66, n. 101332, p. 1-6, oct. 2019. DOI: https://doi.org/10.1016/j.cimid.2019.101332. 
SUTHAR, N. et al. An individual-based model of transmission of resistant bacteria in a veterinary teaching hospital. PLoS One, San Francisco, v. 9, n. 6, e98589, jun. 2014. DOl: https://doi. org/10.1371/journal.pone.0098589.

TURK, R.; SINGH, A.; WEESE, J. S. Prospective surgical site infection surveillance in dogs. Veterinary Surgery, Philadelphia, v. 44, n. 1, p. 2-8, jan. 2014. DOl: https://doi.org/10.1111/j.1532950X.2014.12267.x.

VERWILGHEN, D.; SINGH, A. Fighting surgical site infections in small animals. are we getting anywhere? Veterinary Clinics of North America: Small Animal Practice, Philadelphia, v. 45, n. 2, p. 243-276, mar. 2015. DOl: https://doi.org/10.1016/j.cvsm.2014.11.001.

WALTHER, B.; TEDIN, K.; LüBKE-BECKER, A. Multidrug-resistant opportunistic pathogens challenging veterinary infection control. Veterinary Microbiology, Amsterdam, v. 200, p. 71-78, feb. 2017. DOI: https://doi.org/10.1016/j.vetmic.2016.05.017.

WEESE, J. S.; HALLING, K. B. Perioperative administration of antimicrobials associated with elective surgery for cranial cruciate ligament rupture in dogs: 83 cases (2003-2005). Journal of the

American Veterinary Medical Association, Ithaca, v. 229, n. 1, p. 92-95, jul. 2006. DOI: https://doi. org/10.2460/javma.229.1.92.

WEESE, J. S. A review of post-operative infections in veterinary orthopaedic surgery. Veterinary and Comparative Orthopaedics and Traumatology, Stuttgart, v. 21, n. 2, p. 99-105, 2008. D0I: https:// doi.org/10.3415/VCOT-07-11-0105.

Anexo 1: Checklist de segurança perioperatória aplicado para Medicina Veterinária

\begin{tabular}{|c|c|}
\hline \multirow{9}{*}{$\begin{array}{c}\text { Pré-operatório } \\
\text { (antes da indução anestésica) }\end{array}$} & $\begin{array}{l}\text { Confirmar a identidade do paciente, procedimento a ser feito e } \\
\text { consentimento do tutor. }\end{array}$ \\
\hline & Confirmar se o preparo pré-anestésico recomendado foi realizado \\
\hline & Conferir exames pré-operatórios. \\
\hline & Marcar o sítio cirúrgico (quando necessário). \\
\hline & Alergia a algum fármaco? \\
\hline & $\begin{array}{c}\text { Risco de dificuldade respiratória? Se sim, os equipamentos para } \\
\text { assistência devem estar disponíveis. }\end{array}$ \\
\hline & $\begin{array}{l}\text { Risco de perda de grande quantidade de sangue? Se sim, acesso } \\
\text { adequado e fluídos necessários disponíveis. }\end{array}$ \\
\hline & $\begin{array}{c}\text { Antecipar possíveis eventos críticos que podem ocorrer durante } \\
\text { o procedimento. (Fazer uma lista anexa?) }\end{array}$ \\
\hline & $\begin{array}{l}\text { Garantir que todos os instrumentais estejam devidamente } \\
\text { esterilizados e todos materiais disponíveis. }\end{array}$ \\
\hline
\end{tabular}




\begin{tabular}{|c|c|}
\hline \multirow{4}{*}{$\begin{array}{l}\text { Transoperatório } \\
\text { (antes da incisão inicial) }\end{array}$} & Preparo do sítio cirúrgico (Tricotomia ampla e antissepsia adequada) \\
\hline & $\begin{array}{c}\text { Confirmar verbalmente a identidade do paciente e o } \\
\text { procedimento que será realizado. }\end{array}$ \\
\hline & $\begin{array}{l}\text { Conferir com o instrumentador e volantes todos materiais } \\
\text { disponíveis na mesa de cirurgia e na sala operatória. }\end{array}$ \\
\hline & $\begin{array}{l}\text { Se indicado, antimicrobiano profilático foi administrado entre } \\
\text { 30-60 minutos antes da incisão inicial? }\end{array}$ \\
\hline \multirow{2}{*}{$\begin{array}{l}\text { Transoperatório } \\
\text { (após incisão inicial) }\end{array}$} & $\begin{array}{l}\text { Comunicar à equipe eventos críticos (Hipotensão, Hemorragia } \\
\text { Ativa, Intercorrências Cirúrgicas) }\end{array}$ \\
\hline & Comunicar tempo estimado para fim do procedimento. \\
\hline $\begin{array}{c}\text { Transoperatório } \\
\text { (antes do fechamento da ferida) }\end{array}$ & $\begin{array}{l}\text { Confirmar se todos os materiais utilizados (gazes, compressas, } \\
\text { instrumentos) foram retirados do sítio cirúrgico. }\end{array}$ \\
\hline \multirow[b]{2}{*}{$\begin{array}{c}\text { Pós-operatório } \\
\text { (antes do paciente sair da } \\
\text { sala de cirurgia) }\end{array}$} & $\begin{array}{l}\text { Confirmar se a amostra está devidamente identificada (caso seja } \\
\text { feita alguma coleta no transoperatório). }\end{array}$ \\
\hline & $\begin{array}{l}\text { Revisar os pontos-chave para a recuperação adequada } \\
\text { do paciente (Controle de dor, Terapia Antimicrobiana Pós- } \\
\text { operatória? Internação? Prescrição pós-operatória durante } \\
\text { a internação, Necessidade de oxigênio? Possibilidade de } \\
\text { pneumonia aspirativa?). }\end{array}$ \\
\hline
\end{tabular}

TFonte: Adaptado de WHO, 2009.

Anexo 2. Classificação de feridas cirúrgicas segundo a presença de microrganismos e respectivos exemplos

\begin{tabular}{|c|c|c|}
\hline Classificação & Descrição & Exemplos de procedimentos cirúrgicos \\
\hline $\begin{array}{c}\text { Cirurgias limpas } \\
\qquad(2-5 \%)\end{array}$ & $\begin{array}{l}\text { Não traumática, não infectada, } \\
\text { sem inflamação; sem quebra da } \\
\text { técnica asséptica; fechamento } \\
\text { primário, sem aplicação de } \\
\text { dreno; sem penetração do trato } \\
\text { respiratório, gastrointestinal e } \\
\text { geniturinário. }\end{array}$ & $\begin{array}{l}\text { Esplenectomia, laparotomia exploratória, } \\
\text { excisão de nódulos cutâneos, oncológica } \\
\text { não contaminada/infectada (ex.: lipoma), } \\
\text { artrotomias (osteocondrite dissecante, excisão } \\
\text { artroplástica da cabeça e colo femoral não } \\
\text { traumática), cardiovasculares (persistência do } \\
\text { ducto arterioso, persistência do arco aórtico } \\
\text { direito), cirurgias da coluna não traumáticas } \\
\text { (laminectomias), hérnias não encarceradas } \\
\text { (umbilical, inguinal ou perineal), entre outros. }\end{array}$ \\
\hline
\end{tabular}




\begin{tabular}{|c|c|c|}
\hline $\begin{array}{c}\text { Cirurgias limpas- } \\
\text { contaminadas } \\
(2-5 \%)\end{array}$ & $\begin{array}{l}\text { Traumas sem lesão de } \\
\text { órgãos ocos, não penetrante; } \\
\text { penetração sob condições } \\
\text { controladas de trato respiratório, } \\
\text { gastrointestinal e geniturinário; } \\
\text { aplicação de dreno, presença de } \\
\text { inflamação; mínima quebra da } \\
\text { técnica asséptica. }\end{array}$ & $\begin{array}{l}\text { Colecistoduodenostomia, enterotomia, } \\
\text { cistotomia, gastrotomia, nefrectomia, } \\
\text { enterectomia, cistectomia e gastrectomia sem } \\
\text { tecido desvitalizado, oncológica com processo } \\
\text { inflamatório excessivo e não contaminada, } \\
\text { osteossíntese de fraturas fechadas, ruptura } \\
\text { diafragmática, entre outros. }\end{array}$ \\
\hline $\begin{array}{c}\text { Cirurgias } \\
\text { contaminadas } \\
(5-10 \%)\end{array}$ & $\begin{array}{l}\text { Feridas abertas ou traumáticas } \\
\text { recentes (<4h); perfuração } \\
\text { de trato respiratório, } \\
\text { gastrointestinal e geniturinário } \\
\text { com derramamento de líquido } \\
\text { (<4h); incisão de sítio com } \\
\text { inflamação aguda e não } \\
\text { purulenta; máxima quebra da } \\
\text { técnica asséptica. }\end{array}$ & $\begin{array}{l}\text { Colecistoduodenostomia, enterectomia, } \\
\text { cistectomia e gastrectomia com tecido } \\
\text { desvitalizado ou transgressão grave das } \\
\text { técnicas assépticas e/ou derramamento de } \\
\text { conteúdo (bile, urina e fezes), peritonite } \\
\text { (<4h), piometra não rompida, osteossíntese } \\
\text { de fraturas abertas tipo II e III sem secreção } \\
\text { purulenta e <4h, abscesso hepático não } \\
\text { rompido, oncológica com ulceração e sem } \\
\text { secreção purulenta e amputação por gangrena } \\
\text { seca, entre outros. }\end{array}$ \\
\hline $\begin{array}{l}\text { Cirurgias } \\
\text { infectadas } \\
(>20 \%)\end{array}$ & $\begin{array}{l}\text { Feridas traumáticas antigas } \\
\text { (>4h); Inflamação com } \\
\text { secreção purulenta; Perfuração } \\
\text { de trato gastrointestinal, } \\
\text { geniturinário e respiratório ou } \\
\text { tecido desvitalizado ( }>4 \mathrm{~h}) ; \\
\quad \text { Contaminação fecal. }\end{array}$ & $\begin{array}{l}\text { Peritonite séptica (>4h); piometra rompida } \\
\text { (>4h); ruptura intestinal ou de vesícula biliar } \\
\text { causada por colecistite necrotizante ou trauma } \\
\text { (>4h); oncológica contaminada com secreção } \\
\text { purulenta; amputação por gangrena úmida, } \\
\text { entre outros. }\end{array}$ \\
\hline
\end{tabular}

T Fonte: Adaptado de GLOBAL GUIDELINES FOR THE PREVENTION OF SURGICAL SITE INFECTION (2016); SINGH; WEESE, 2017; VERWILGHEN; SINGH, 2015. 